\title{
A novel drifter designed for use with a mounted Acoustic Doppler Current Profiler in shallow environments
}

\author{
Julia C. Mullarney ${ }^{1 *}$ and Stephen M. Henderson ${ }^{2}$ \\ ${ }^{1}$ Department of Earth and Ocean Sciences, University of Waikato, Hamilton, New Zealand \\ ${ }^{2}$ School of the Environment, Washington State University, Vancouver, Washington, U.S.A
}

\begin{abstract}
We present a novel design for a surface drifter, mounted with a pulse-coherent Acoustic Doppler Current Profiler (ADCP) for measuring near-surface (depths 0.18-1 m) flows. During repeated drifter deployments over the tidal flats of Skagit Bay, the mounted ADCP recorded high quality and high resolution profiles of velocity in depths as shallow as $0.4 \mathrm{~m}$. Depth-dependent velocities revealed regions of vertically sheared currents and wave motions not resolved by surface drifters alone. Although the cost of ADCPs is substantial, the drifter bodies were low cost, robust, and of simple construction.
\end{abstract}

Lagrangian drifters have been used for many years to measure surface currents over a wide range of spatial and temporal scales. The cost and design of these drifters varies depending on the application. Building on deployments of drifters in the deep ocean (e.g., Davis 1985), and taking advantage of cheap and accurate modern GPS systems, researchers have recently developed low-cost drifters for use in nearshore, estuarine (Johnson et al. 2003; Austin and Atkinson 2004; Thomson 2012) and surfzone (Schmidt et al. 2003; MacMahan et al. 2009) environments. However, the drifter designs above typically have drafts of around 0.5 to $1 \mathrm{~m}$, rendering them unsuitable for use in very shallow flows.

Modern compact Acoustic Doppler Current Profilers (ADCPs) are capable of measuring velocities over range bins of a few centimeters. The small size, high resolution, and short blanking distance of these instruments have raised the possibility of using drifter-mounted ADCPs to resolve near-surface flows, even in very shallow environments.

We present a novel design for surface drifters intended for use with a Nortek Aquadopp ADCP. The design yielded highresolution vertical profiles of velocity, as the drifter tracked the propagation of baroclinic surface fronts over very shallow tidal flats (water depths of $0.2-1 \mathrm{~m}$ ). The highest bin of the velocity profiles was around just $0.18 \mathrm{~m}$ below the water sur-

*Corresponding author: E-mail: juliam@waikato.ac.nz

\section{Acknowledgments}

We thank Kassi Dallavis for assistance with drifter assembly and field work and Chris Eager, Nate Raynor, Drew Becker, Chris Schleffler, and Lisa Hodges for assistance with the field work. Funding was provided by the Office of Naval Research and the State of Washington.

DOI 10.4319/lom.2013.11.438 face, a notable improvement over use of majority of the above designs, which would result in a smallest measurement depth of around $0.62 \mathrm{~m}$ below the surface (based on a representative $0.5 \mathrm{~m}$ drifter draft plus $0.07 \mathrm{~m}$ ADCP draft plus $0.05 \mathrm{~m}$ blanking distance). The Thomson (2012) drifter used an uplooking ADCP, which allowed measurements to be made close to the water surface; however, the drifter had a $1.25 \mathrm{~m}$ draft preventing its deployment in very shallow water depths. For water depths of between $0.15 \mathrm{~m}$ and $0.18 \mathrm{~m}$, the ADCP-mounted drifter described here was still freely advected, but in this case, ADCP measurements were not obtained. The drifters were robust and of very simple construction, requiring only use of hand tools and using off-the-shelf components. Although the cost of the ADCP was substantial (exceeding US\$10,000), the cost for each drifter body was minimal (less than US\$100, similar to costs of the other drifters above). Drifter positions were tracked by an inexpensive off-the-shelf GPS logger $(<$ US\$100).

\section{Materials and procedures}

Drifters (Fig. 1) were constructed from sections of PVC pipe (outside diameter $60 \mathrm{~mm}$ chosen to ensure a low-draft) and connectors. Pipe, connectors and PVC cement are easily obtained and assembly was straightforward. Crossing pipes provided attachment points for the ADCP, which was secured using hose clamps. The width of the drifter $(0.72 \mathrm{~m})$ was chosen to ensure the drifter body extended beyond the ends of the ADCP, providing protection in the event of collision with a solid object. To minimize windage, drifters were filled with granular ballast (feedcorn) until nearly neutrally buoyant, with only the top $10 \mathrm{~mm}$ of the body (corresponding to about 8\% of drifter volume) above the water surface. The drifters appeared to be streamlined with the water surface because of 
(a)

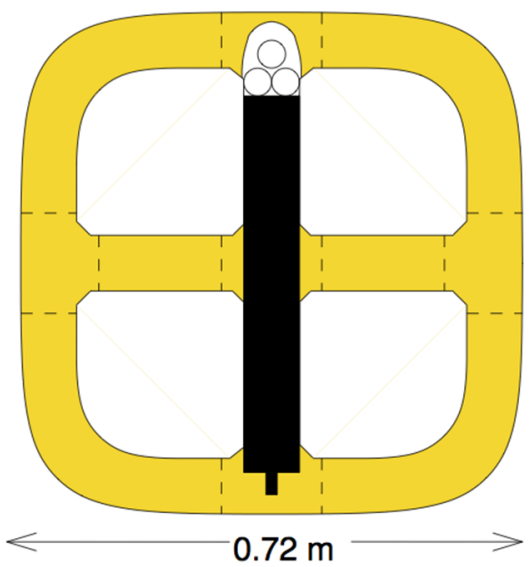

(c)

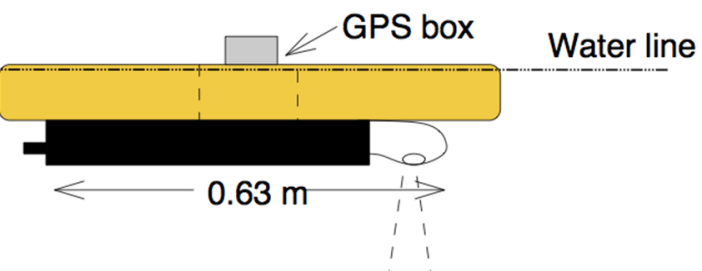

(b)

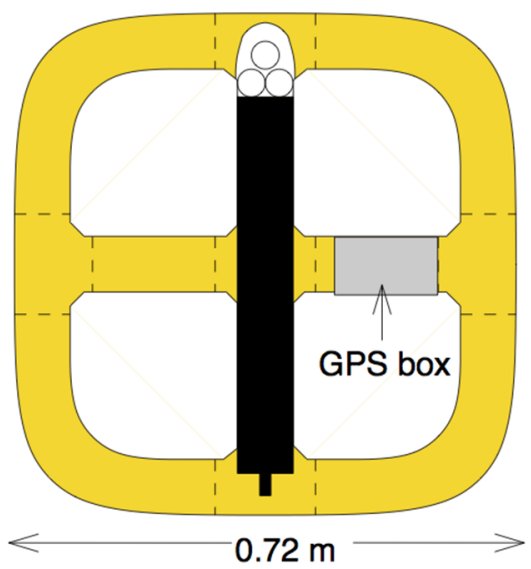

(d)

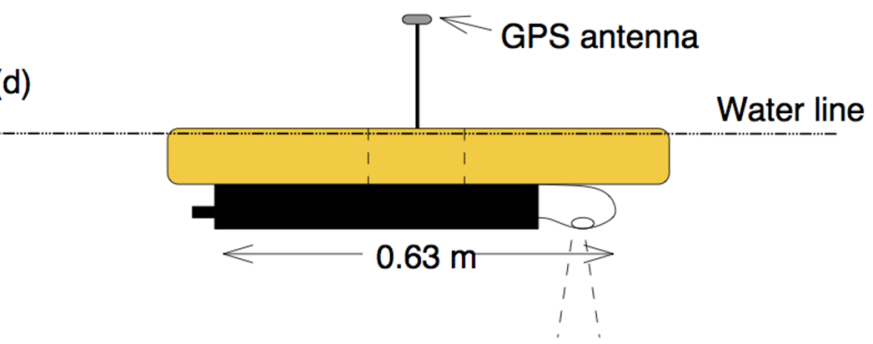

Fig. 1. Schematic of drifter design (approximately to scale). Plan view from below for GPS without (a) and with (b) external antenna. Side view for drifters with GPS without (c) and with (d) external antenna. Dashed lines indicate joins.

(a)

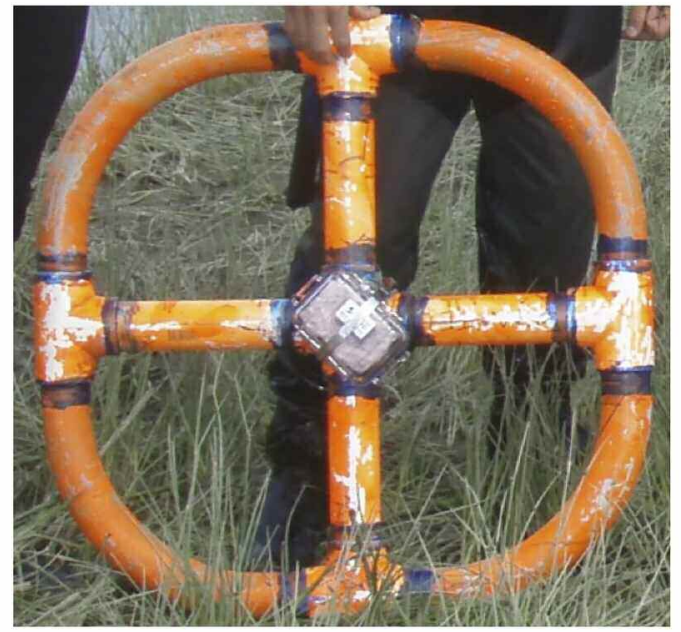

(b)

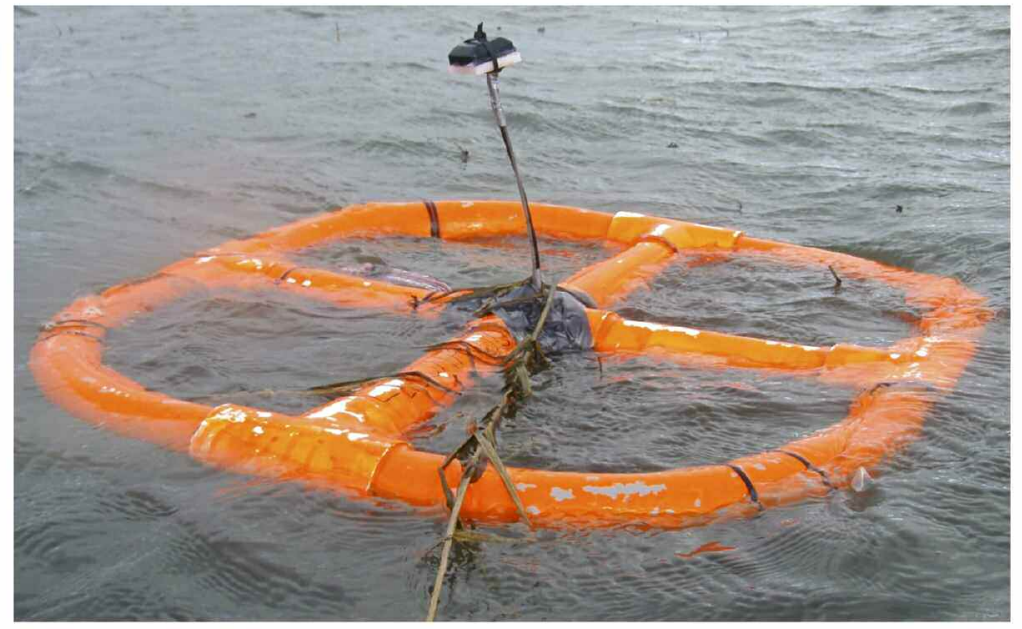

Fig. 2. (a) Photograph of drifter without external antenna out of water. (b) Photograph of drifter in water (with external antenna). In (b), wind blew from right to left, and vegetation floating on the water surface collected on the upwind side of the drifter.

the circular cross-section of the pipes. The draft of the drifter itself is little more than the $60 \mathrm{~mm}$ diameter of the tubing and the addition of the ADCP increased the draft to about $140 \mathrm{~mm}$. On the top side of the drifter, we attached a waterproof box (Pelican 1010 Microbox) of dimensions 111(L) $\times 73(\mathrm{~W}) \times 43(\mathrm{H})$ $\mathrm{mm}$ containing the GPS unit; we used both i-Blue PhotoMate
887 Mini loggers (Figs. 1a and 2a) and Emtac Trine II's (Figs. 1b and 2b) sampling at 1 and $0.33 \mathrm{~Hz}$, respectively, and both costing < US\$100. Comparison between drifter motions and velocities measured by nearby fixed instruments did not show clear evidence of wind slip (Section 3). For the Trine logger, which had dimensions $90 \times 50 \times 21 \mathrm{~mm}$ attached to an external 
antenna of dimensions $45 \times 37 \times 25 \mathrm{~mm}$, further reductions in windage were achieved by mounting the Pelican case and logger underwater (the antenna was placed on a small wire 150 $\mathrm{mm}$ above the surface, Fig. 2b). For the iBlue unit, which had a built-in antenna (hence the waterproof container required a clear lid), future reductions in windage could be achieved by replacing the Pelican case with a smaller waterproof container (the iBlue logger had dimensions $44 \times 20 \times 15 \mathrm{~mm}$ ). Both units used WAAS-enabled differential GPS technology to give positions to an accuracy of $\sim 3 \mathrm{~m}$.

Downward-looking ADCPs (2 MHz Nortek Aquadopps with right-angle head) were attached to drifters with transducers situated approximately $0.16 \mathrm{~m}$ below the water surface. The Aquadopp ADCP was approximately neutrally buoyant, and consequently, did not significantly affect protrusion of the drifter above the surface. The Aquadopps operated in 'pulsecoherent' mode with range $0.75 \mathrm{~m}$. Pulse-coherent instruments use a pair of short acoustic pulses with known time lag and calculate the complex autocovariance function between the two echoes to determine the Doppler-induced phase shift, which provides a direct measure of velocity. The short pulses provide high spatial resolution, while the interval between the pulses provides low noise by permitting time for movement of scatterers, yielding substantial phase shifts. However, there is an inherent limitation on the product of the profiling range and the unambiguous velocity that can be resolved, i.e., the faster the flow, the shorter the range than can be profiled (Lhermitte and Serafin 1984; Lohrmann et al. 1990; Zedel et al. 1996).

High resolution $(0.025 \mathrm{~m}, 0.05 \mathrm{~m}$, and $8 \mathrm{~Hz}$, vertical, horizontal, and temporal resolution) measurements of velocity were recorded over bursts of 512 s, with 3-s gap between consecutive bursts. Post-processing of pulse-coherent ADCP data removed bins with low $(<50 \%)$ mean correlations. An unwrapping routine removed velocity ambiguities along each beam by minimizing velocity differences between adjacent range bins. For results presented below, the vertical shear in horizontal velocity components was calculated by differencing range bins over a vertical separation of $0.1 \mathrm{~m}$ and smoothing with a 10-s moving average. Owing to the lack of external tracking, the drifters were closely monitored and spraypainted fluorescent orange to improve their visibility.

\section{Assessment}

The drifters were tested over several deployments on the tidal flats in Skagit Bay, Washington (Fig. 3a) during the summers of 2008 and 2009. The broad tidal flats are exposed at low tides, and are characterized by shallow flow and networks of subtidal channels. A variety of configurations were used with/without ADCP attached and with/without GPS with antenna. Drifter tracks are shown in Fig. 3b, and deployments are also summarized in Table 1. Ebb tides occurred early in the morning, and for convenience, most deployments were conducted during daytime flood tides. During the few ebb tide deployments, no drifters had ADCPs attached (black and red lines, Fig. 3b).
Surface fronts often formed during the early stages of flood tide and tended to align on the edge of a subtidal channel (low tide channel depth around $0.7 \mathrm{~m}$ ). These fronts often remained trapped on or close to the channel edge for around an hour after flooding of the tidal flats (Mullarney and Henderson 2011). Typically, we released the drifters on the tidal flats shortly after the onset of flood tide, when local depth was about $0.3 \mathrm{~m}$. Drifters then were advected toward the channel and became trapped on the channel-edge front (along with seaweed and other flotsam) by convergent surface flows (releases 1,2,5,7, Table 1, Fig. 3b). The drifters were then advected along the front. Usually, drifters were collected on reaching the northern end of the channel; either from the channel, or occasionally after, they had become entangled in saltmarsh vegetation. On one occasion, a drifter traveled up a subsidary channel into the North Fork of the Skagit River, whereupon it became caught in a debris eddy (light blue line, Fig. 3b). As flood tide progressed, fronts departed from the edge of the channel and propagated westwards across the flats as the leading edge of a thin fresh surface plume (Mullarney and Henderson 2011). During deployment 6, drifters were released a second time near the channel edge after the westward spreading of the plume had commenced. These drifters propagated to the front, where they were trapped by the surface convergence, and traveled westward with the front for over a kilometer (dark blue lines, Fig. 3b). The surface fronts were commonly observed on days with low to moderate winds. However, on days with high winds (not shown), fronts were not observed and drifters were advected with prevailing winds and surface flows into the salt marsh vegetation toward the East (Mullarney and Henderson 2011).

In this article, we focus on velocity measurements from a single flood tide which exhibited 'front-trapping and release' behavior (releases 5 and 6, green and dark blue tracks, Fig. 3b). Four drifters were released, two of which had ADCPs attached. There was no discernable difference in drifter tracks or speeds from drifters that had ADCPs attached and those that did not (Fig. 3c).

Winds were measured by a weather station located on a small hill in 2008 (white square, Fig. 3b) and at a height of 4.2 $\mathrm{m}$ above the flats during 2009 (white circle, Fig. 3b). During drifter releases 5 and 6, winds were relatively light $(0-5.6 \mathrm{~m} / \mathrm{s}$, Figs. $4 \mathrm{a}$ and $5 \mathrm{a}$ ). The drifters were stable: the mean (standard deviation) pitch and roll of the ADCP for the release shown in Fig. 4 were $0.86^{\circ}\left(0.12^{\circ}\right)$ and $-0.55^{\circ}\left(0.06^{\circ}\right)$, respectively. During the release shown in Fig. 5 , mean (standard deviation) pitch and roll of the ADCP were $0.87^{\circ}\left(0.15^{\circ}\right)$ and $-0.47^{\circ}\left(0.15^{\circ}\right)$. The ADCP heading measurements show that the drifters rotated slowly, suggesting a vertical vorticity of order $10^{-3}-10^{-1} \mathrm{~s}^{-1}$ (Fig. 6a). As the drifter traveled along the edge of the main channel between 38 and $43 \mathrm{~min}$, the drifter rotated counterclockwise, suggesting faster flow in the channel, consistent with observations (Mullarney and Henderson 2011). Given a front width of a few meters, the drifter rotation rate suggests a plau- 

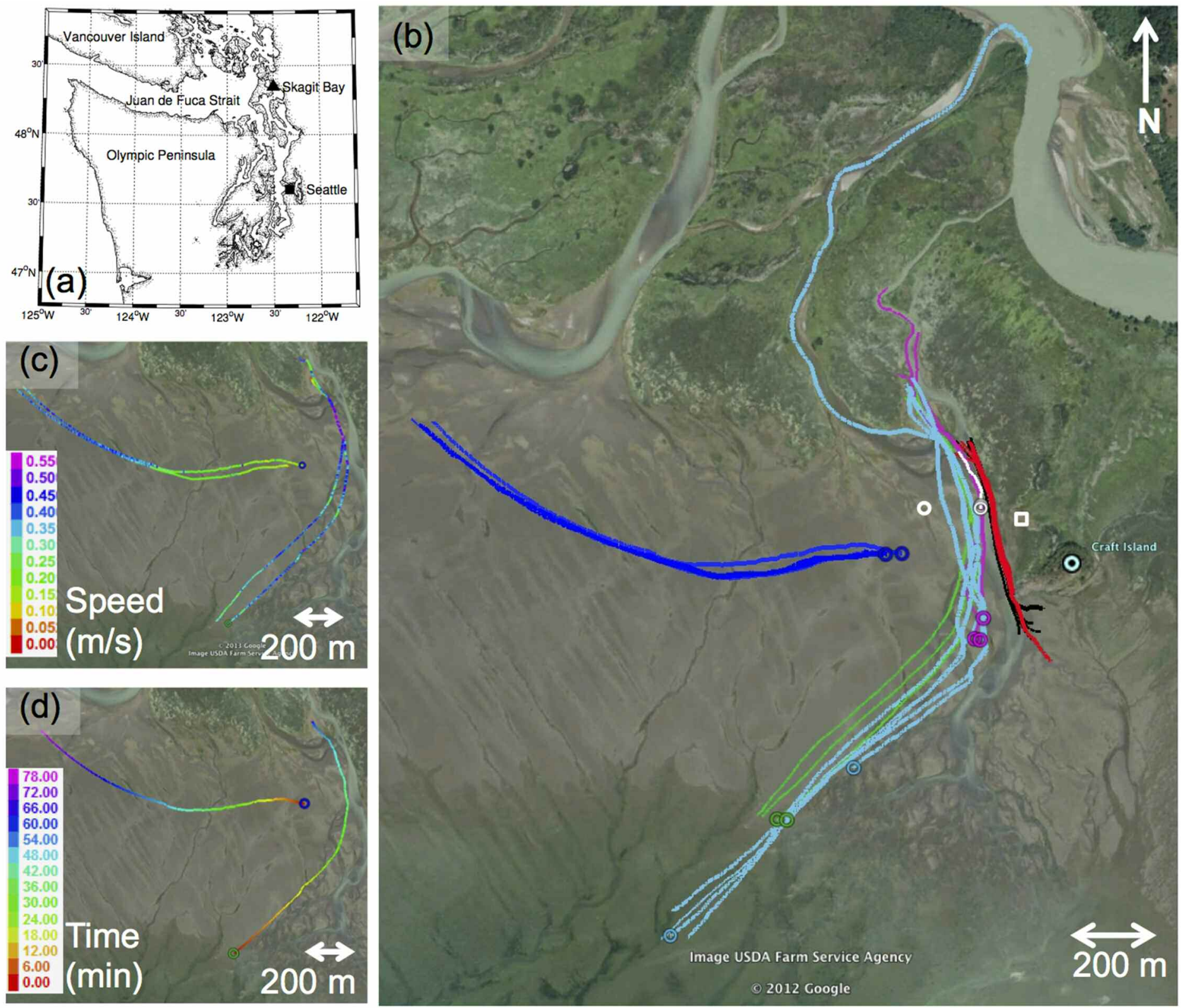

Fig. 3. (a) Location of Skagit Bay. (b) Tracks from drifter deployments, corresponding to those listed in Table 1. Each color corresponds to a different deployment. Thick (thin) lines show drifters using GPS units without (with) and external antenna (Figs. 1 and 2). Tracks with colored circles at the start show drifters, which had an ADCP attached. Black and red lines show ebb tide releases (drifters moved Southwards); all other colors show flood tide releases (drifters moved Northwards or Westwards). Google Earth Imagery from 26 June 2009 (we note the locations of the channel edges moved between deployments). The thick white square (circle) shows the location of the weather station in 2008 (2009) located on a small hill (located at a height of $4.2 \mathrm{~m}$ above the flats). (c) Comparison of two drifter tracks from deployments 5 and 6 for drifters with (circle at start of track) and without an ADCP attached. Tracks are colored by drifter speeds (obtained by differencing GPS positions and smoothing over 10 s.). (d) Drifter tracks corresponding to the deployments shown in Figs. 4 and 5, with track colored by time after release (min).

sible cross-front change in along-front velocity of a few tens of $\mathrm{cm} \mathrm{s}^{-1}$. After the front was released from the channel edge and propagated out across the flats, the drifter was redeployed behind the front and rotated rapidly until it rejoined the front at around time $=15 \mathrm{~min}$, after which the heading remained relatively stable (Fig. 6b, $t>18 \mathrm{~min}$ ), suggesting that the surface convergence may hold the ADCP parallel to the front.
The location of the seafloor was identified from a clear local maximum in acoustic backscatter intensity (Figs. $4 \mathrm{~b}$ and $5 \mathrm{~b}$ ). Although some data had to be discarded because of low correlations, data quality was mostly high: for the first release, each burst had at least $69 \%$ of data from over the three beams with correlations over 70\% (and at least $88 \%$ of data from each burst had correlations over 50\%, Fig. 4c). Similarly, for the second 
Table 1. Summary of drifter releases.

\begin{tabular}{|c|c|c|c|c|c|}
\hline Release number & Date & $\begin{array}{c}\text { Number of } \\
\text { drifters }\end{array}$ & $\begin{array}{c}\text { Number of } \\
\text { drifters with ADCP }\end{array}$ & $\begin{array}{c}\text { Flood or } \\
\text { ebb release }\end{array}$ & Line color (on Fig. 3 ) \\
\hline 1 & 26-Sep-08 & 3 & 3 & flood & pink \\
\hline 2 & 27-Sep-08 & 2 & 2 & flood & white \\
\hline 3 & 28-May-09 & 5 & 0 & ebb & black \\
\hline 4 & 28-May-09 & 5 & 0 & ebb & red \\
\hline 5 & 18-Aug-09 & 4 & 2 & flood & green \\
\hline 6 & 18-Aug-09 & 4 & 2 & flood & blue \\
\hline 7 & 19-Aug-09 & 5 & 2 & flood & light blue \\
\hline
\end{tabular}

(a)

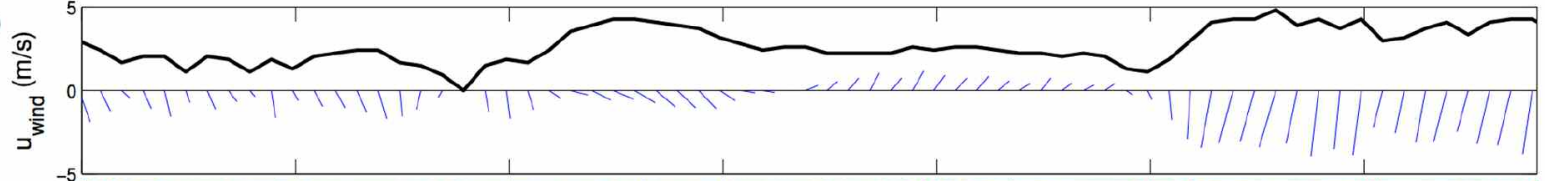

(b)

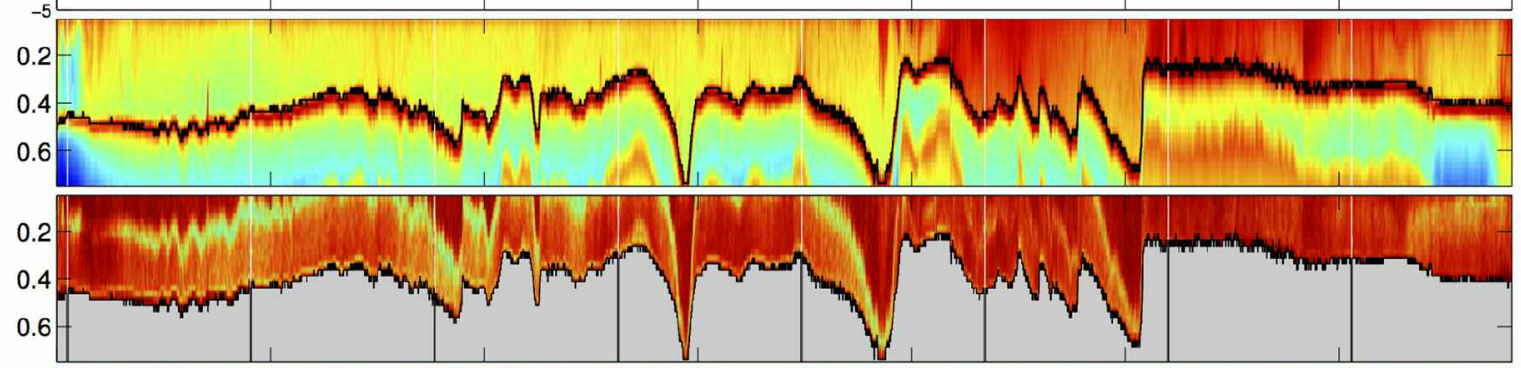

(d)
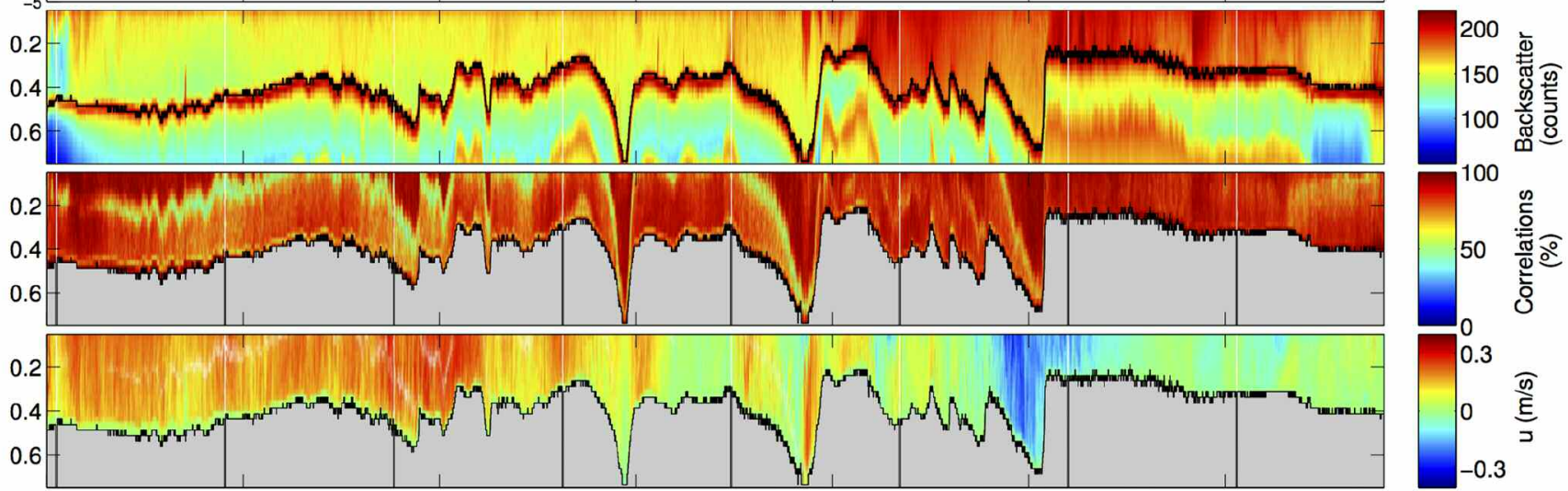

(e)

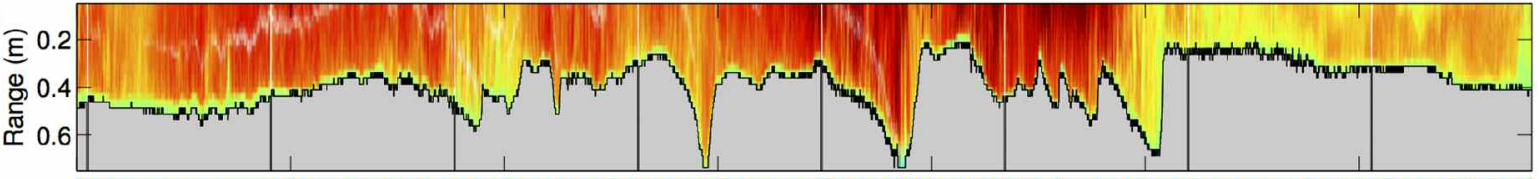

(f)

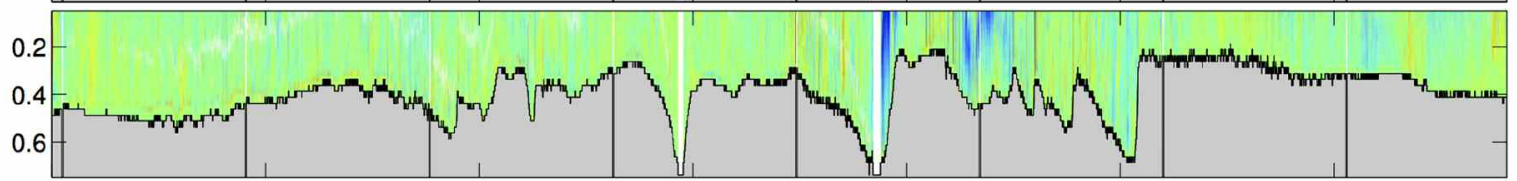

(g)

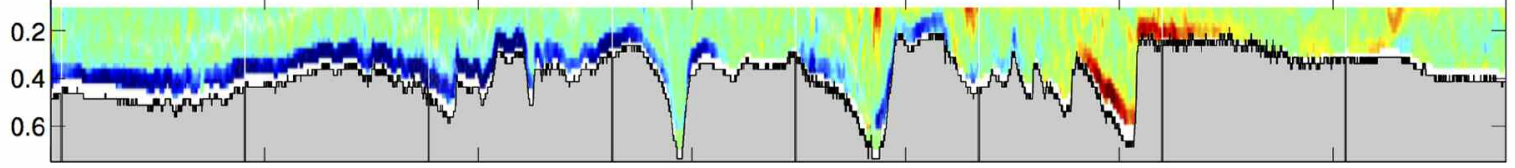

(h)

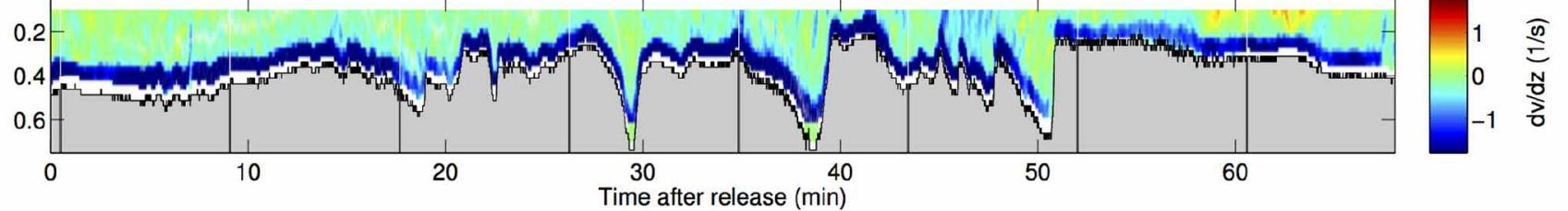

Fig. 4. (a) Wind vectors and speeds (black line) from the weather station on the flats (Fig. 3b). Data from an ADCP in release 5 (green lines, Fig. $3 b$ ). (b) Backscatter (mean over three beams). Black line indicates bottom as identified by algorithm. (c) Correlations (mean over three beams). (d) East-West velocity, (e) North-South velocity, (f) vertical velocities (g) East-West velocity shear, (h) North-South velocity shear (shears smoothed with a 10-s moving average filter). Black vertical lines indicate gap between bursts. White regions in velocity plots indicate bins in which mean correlations $<50$ (or the two short time periods in which the ADCP did not see the bottom at $t \sim 29,39 \mathrm{~min}$ ). The $z$-axis is positive downwards. 
(a)

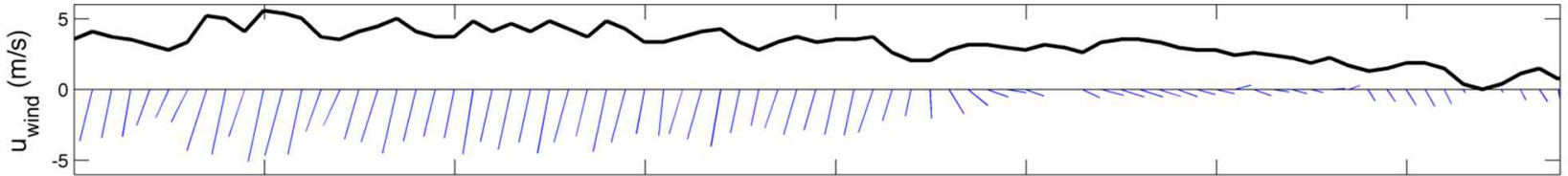

(b)

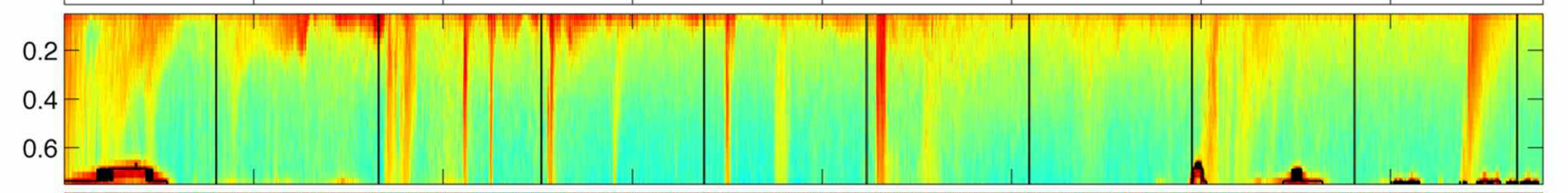

(c)

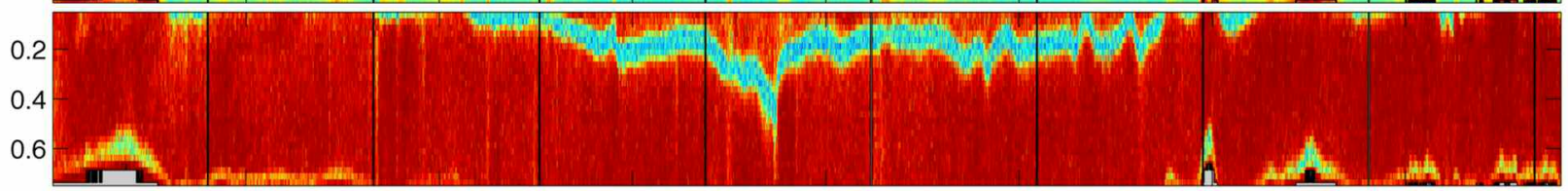

(d)
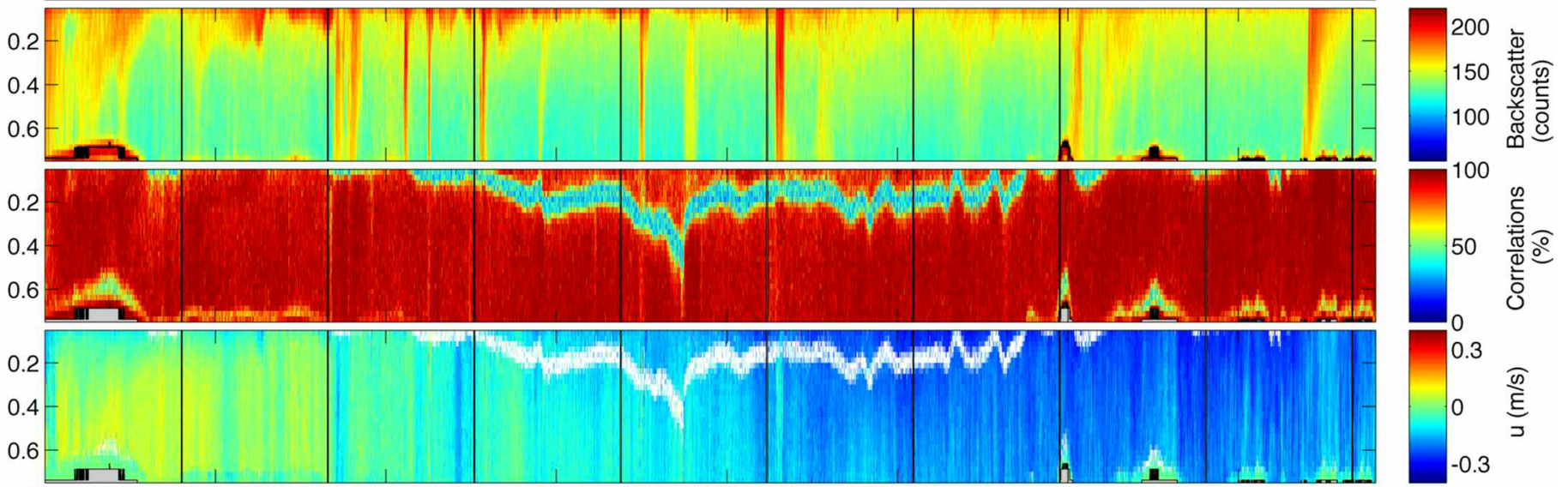

(e)

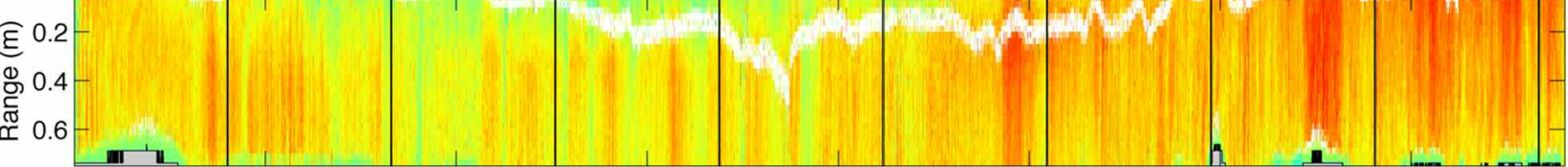

(f)

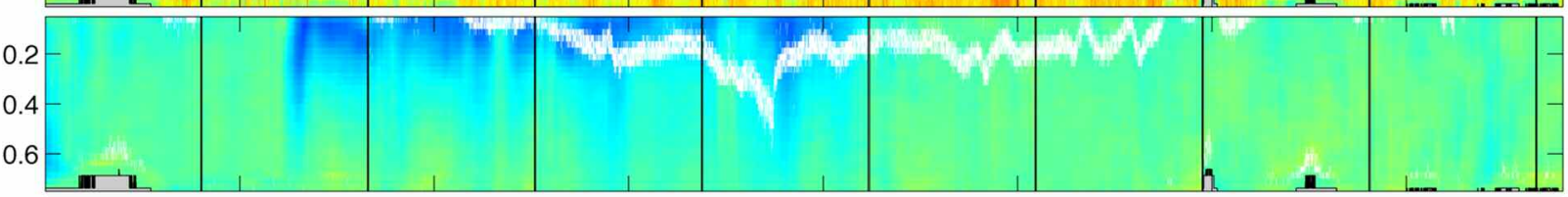

(g)

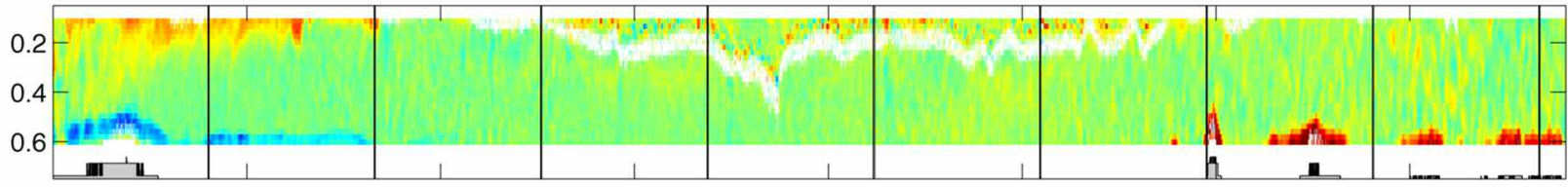

(h)

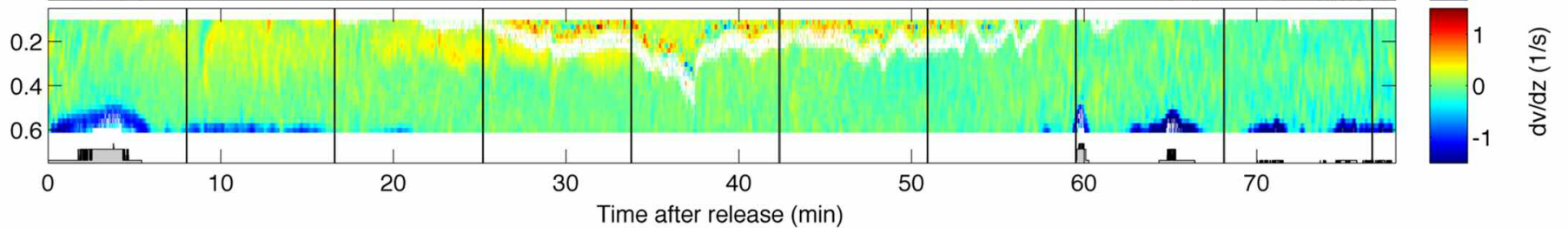

Fig. 5. (a) Wind vectors and speeds (black line) from the weather station on the flats (Fig. 3b). Data from ADCP from deployment 6 (dark blue lines, Fig. 3b). (b) Backscatter (mean over three beams). Bottom reflections were unclear because depth usually exceeded instrument range. (c) Correlations (mean over three beams). (d) East-West velocity, (e) North-South velocity, (f) vertical velocities (smoothed with $60 \mathrm{~s}$ moving-average filter), (g) East-West velocity shear, (h) North-South velocity shear (shears smoothed with a 10-s moving average filter). Black vertical lines indicate gap between bursts. White regions in velocity plots indicate bins in which mean correlations $<50$. The $z$-axis is positive downwards.

release, each burst had at least $77 \%$ data from over the three beams with correlations over $70 \%$ and at least $86 \%$ of data from each burst had correlations over 50\% (Fig. 5c). Velocities in bins in which mean correlations over the three beams were $<50 \%$ have been excluded from the figures. This quality control criteria proved sufficient to remove the majority of bad data points, however, we note a few bad data points are still apparent in the velocity shear measurements for deployment 6 (Fig. $5 \mathrm{~g}, \mathrm{~h}$ ).

Of note were thin bands of low correlation data, whose elevation varied with the total water depth (Figs. $4 \mathrm{c}$ and $5 \mathrm{c}$ ). These bands were likely caused by the reflection off the bed of the first ping of a pulse-pair interfering with the return signal of the second ping (Lohrmann and Nylund 2008). As the drifter became trapped in the front at the edge of the tidal channel ( $40 \mathrm{~min}$ after first release, Fig. 4c), backscatter increased throughout the water column, possibly indicating reflections from organic detritus visible in the frontal convergence, or from sharp frontal gradients in salinity and temperature.

Because the drifter moved with the surrounding water, raw $\mathrm{ADCP}$-measured velocities were small. Consequently, phase 

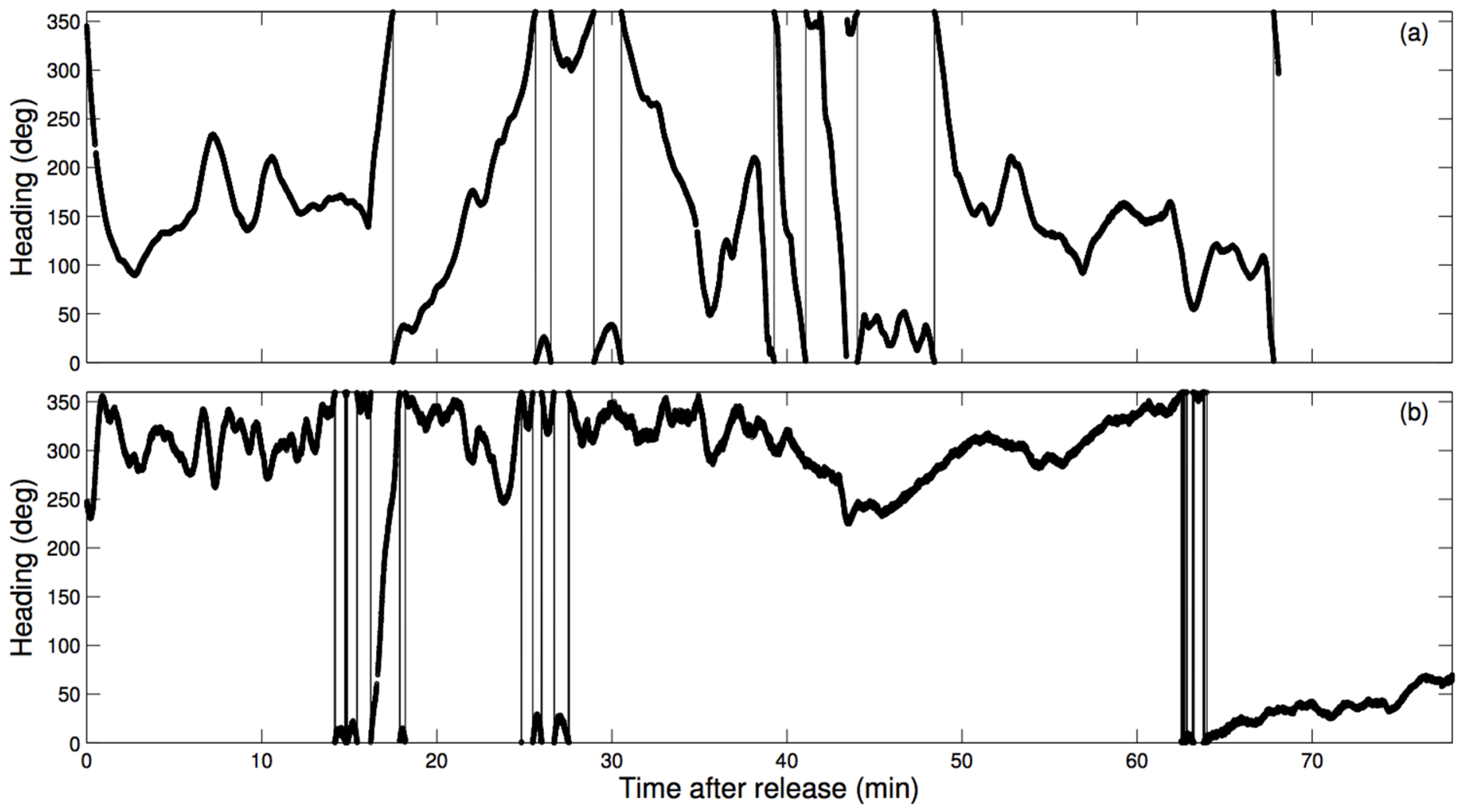

Fig. 6. ADCP heading from a drifter from deployment 5 (a) and 6 (b). The measurements are from the same ADCPs as those shown in Figs. 4 and 5.

wraps (which commonly afflict pulse-coherent measurements of high-velocity flow) posed no difficulties. Along-beam velocities were rotated into East-North-Up (ENU) components, and the velocity of the drifter was added to give velocity components relative to Earth coordinates. Drifter motion was calculated using two methods. The first method removed each component of the apparent bed velocity measured by the moving ADCP. Horizontal components of apparent bed velocity were smoothed with a $20 \mathrm{~s}$ moving-average. However, to retain wave motions, the vertical velocities were not smoothed. The second method calculated horizontal drifter velocities by differencing GPS positions and smoothing each velocity component using a 60-s moving average. This second technique was applied in deeper water, in which the ADCP did not 'see' the bed (depth > range), as was the case during most of deployment 6 (Fig. 5). However, the wave-frequency vertical velocities and vertical motion of the drifter could not be calculated using this method. The bottom tracking method was more accurate and hence bottom tracking was used to determine drifter motion whenever possible with position differencing used otherwise. There was generally good agreement between horizontal components of drifter velocity calculated from the two methods for all deployments in which the bed was within the ADCP range as is shown for deployment 5 in Fig. 7. Nonetheless, there were two regions of discrepancies between the methods. Times when drifter velocities are close to 0 ( $t>60 \mathrm{~min}$ ) are not well resolved by position differencing (owing to gps resolution of position, $\mathrm{dx} \approx 0.073 \mathrm{~m}$ and $\mathrm{dy} \approx$ $0.11 \mathrm{~m}$ ). Small errors in GPS positions or ADCP compass headings could also contribute to discrepancies between methods. Such discrepancies are observed around $t \approx 40-42$ min when the drifter was traveling close to Northwards, the calculated Eastward components of drifter velocities were small and were oppositely signed between the two methods.

Overall trends in ADCP-measured horizontal velocities could be anticipated by inspection of drifter tracks (Fig. 3b). During the first drifter release, ADCP-measured velocities were mostly directed northward (Fig. 4e), consistent with the northward drifter motion (Fig. 3b). The overall trend of ADCPmeasured East-West velocities, from Eastward in the first 20 min to Westward after $50 \mathrm{~min}$ (Fig. 4d), was also consistent with the drifter track (Fig. 3b). However, ADCP measurements reveal a variety of additional flow features not resolved by simply tracking the surface drifter motion. For example, measurements of shear of horizontal velocity components (Figs. $4 \mathrm{~g}, 4 \mathrm{~h})$ reveal the highly sheared flow above the bottom boundary layer. However, we note sidelobe effects may bias the velocity measurements in the vicinity of the bed toward zero, and hence, the shear estimates close to the bed may be slightly biased toward high values. In the rest of the water column, depth variability ranges from nearly depth-uniform flow (e.g., $\mathrm{t} \approx 13 \mathrm{~min}$, Fig. $4 \mathrm{~h}$ ) to sheared flow closer to the surface 

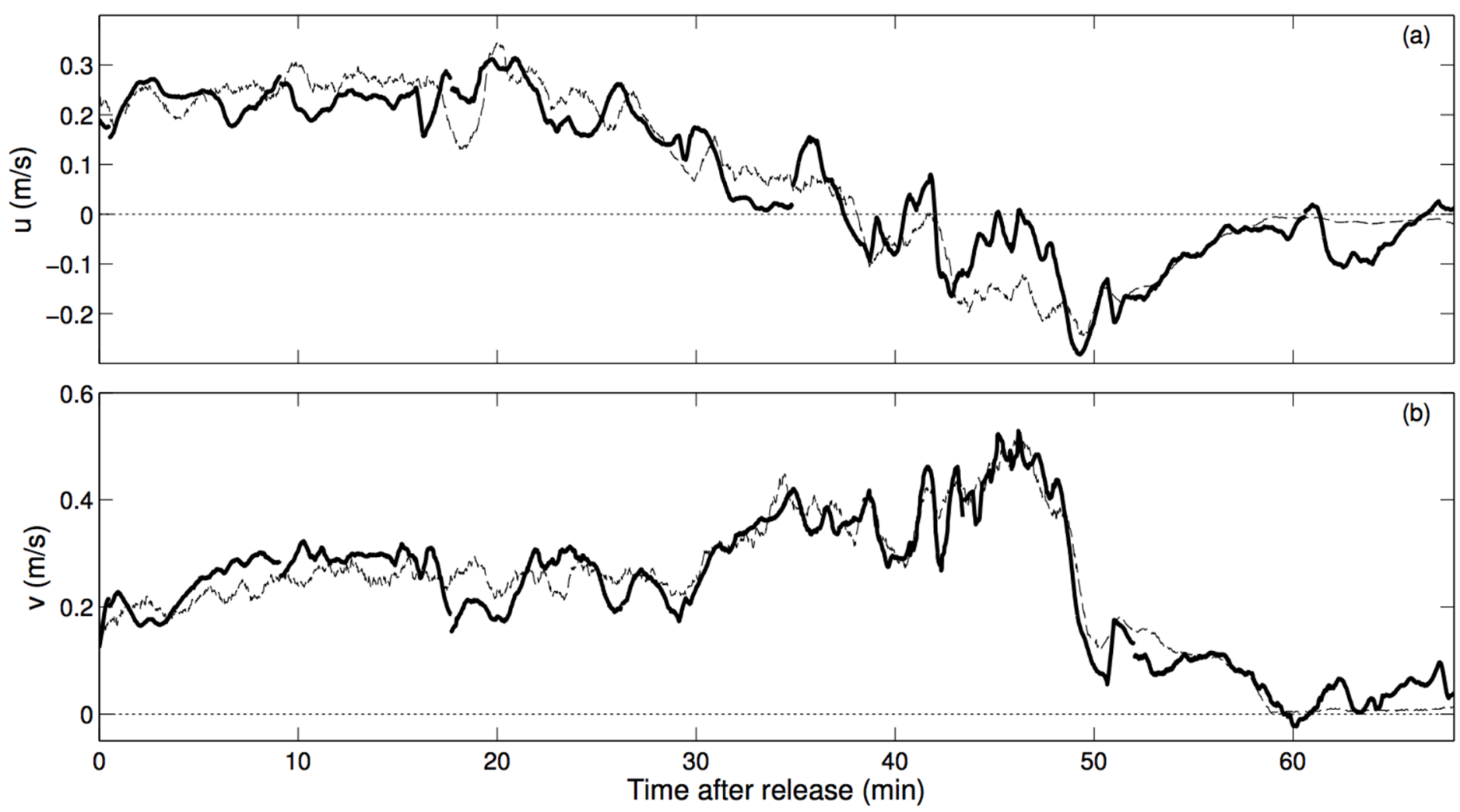

Fig. 7. Drifter velocities for the release show in Fig. 4. (a) East-West, (b) North-South. Velocities calculated from the apparent velocity of the bed (thick lines) and differencing GPS positions (thin dashed lines). Velocities became close to zero at around $t=60$ min because of drifters getting caught in salt marsh vegetation.

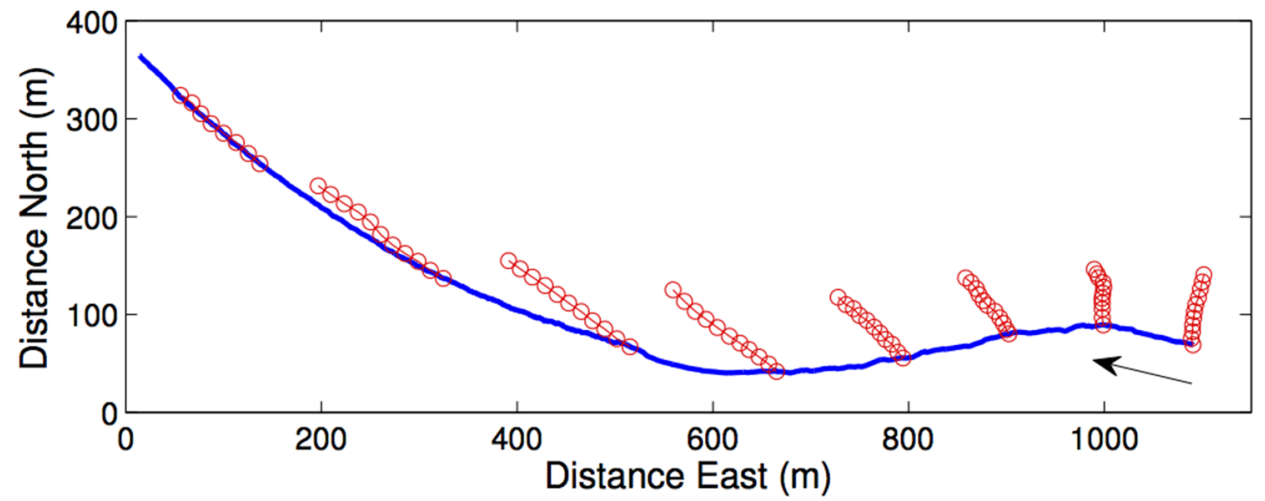

Fig. 8. Drifter track (blue solid line) for a drifter in deployment 6 (corresponding to the release shown in Fig. 5). Progressive vectors from ADCP data (red circles are plotted from 1 min mean velocities) showing depth-averaged velocities for each 10 min time interval. The black arrow shows direction of drifter propagation.

(e.g., $\mathrm{t} \approx 59$ to $64 \mathrm{~min}$, Fig. $4 \mathrm{~h}$ ). Another striking feature is a sudden transition toward sheared westward flow at about $\mathrm{t} \approx$ $38 \mathrm{~min}$, as the drifter crossed the edge of a small channel (Fig. $4 \mathrm{~g}$ ). For the second release (Fig. 5), the plume became trapped in the front at $t \approx 15 \mathrm{~min}$. Once trapped, the drifter was advected westwards at the head of the propagating fresh surface plume. The horizontal velocities reveal sheared flow consistent with propagation contrary to the incoming tidal flow
(Figs. 5d, 5g; t $\approx 0$ to $20 \mathrm{~min}$ ) (Mullarney and Henderson 2011). The drifter turned northwards at $t \approx 45$ min coincident with a weakening of the winds (Fig. 5a). At this time westward velocities (Fig. 5d) strengthen throughout the water column, consistent with freshwater flow pushing out from the subtidal channels and in agreement with measurements from boat transects from this location (Henderson and Mullarney in prep). Previous work (Mullarney and Henderson 2011) 
(a)
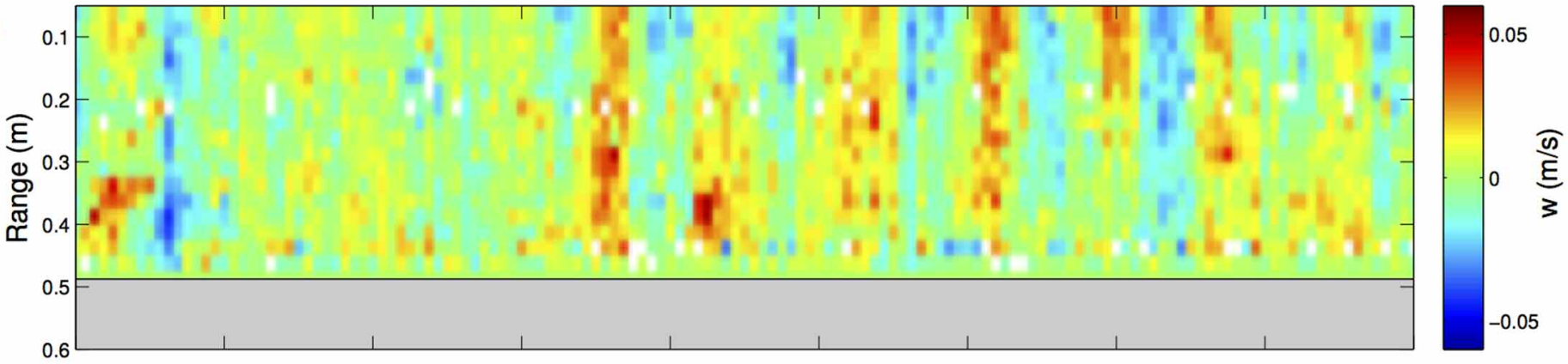

(b)

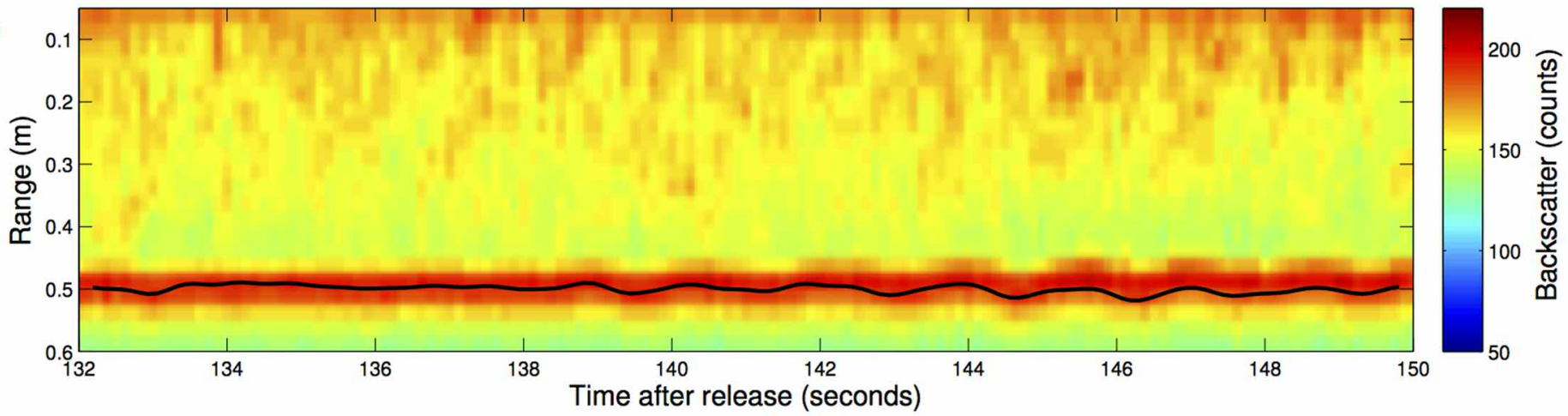

Fig. 9. (a) Close up of vertical velocities from the ADCP on drifter in deployment 5 (Fig. $4 \mathrm{f}, t=2.2$ to 2.5 min) showing the vertical velocities generated by the small wind waves. (b) Surface elevations (black line) vertically offset by the mean water depth superimposed on backscatter (mean over three beams). The surface elevations were obtained assuming linear wave theory depth dependence for velocity (with a cutoff frequency of $1.5 \mathrm{~Hz}$ ) and integrating.

demonstrated that moderate winds can modify the propagation of the thin plume by retarding and even reversing the flows in the top portion (top $0.2 \mathrm{~m}$ ) of the water column-the region in which the drifter sits. A variation of $0.05-0.1 \mathrm{~m} / \mathrm{s}$ in water velocity over the top $0.2 \mathrm{~m}$ of the water column is standard (Henderson and Mullarney 2013). Therefore, it is unsurprising that the winds affect the drifter motion and do not necessarily indicate wind slippage.

The shear dispersion of the flows is most clearly captured in deployment 6 . Fig. 8 shows the strong westward propagation of the drifter (blue line) as it sat in the thin fresh surface plume above the northward tidal flow (depth-averaged progressive vectors from $\mathrm{ADCP}$ velocities are shown by red circles split into 10 min segments). Initially, the flow was strongly sheared with faster surface flows (blue line segments longer than the red segments of the depth-averaged flows, Fig. 8). However, as the flood tide progressed, velocities became closer to depthuniform (red vectors become closer in both length and direction to blue drifter track).

ADCPs also measured vertical velocities, which cannot be measured by simply tracking surface drifter motion. In Fig. 4f, ADCP motion is removed using ADCP measurements of bed velocity, and vertical velocities are not shown at times $(\mathrm{t} \approx 38$ min) when depths exceeded the ADCP range. The most striking measured vertical flow was an intense downwelling near the channel-edge at times ( $t \approx 39$ to $45 \mathrm{~min}$ ) when strong shear was also observed. At this location, previously published observations from fixed instruments show the presence of a surface front, with dense saltwater flowing under a fresher surface layer, and cascading down into the channel from the tidal flats (Mullarney and Henderson 2011). Small wind waves ( $\mathrm{w}=$ $10-30 \mathrm{~mm} / \mathrm{s}, \sim 1.7 \mathrm{~s}$ period) can also be seen (Fig. 9a). Wave heights of a few centimeters (estimated from measured velocities) match measured wave-frequency variations in water depth (Fig. 9b), which suggests that in addition to providing unique high-resolution velocity profiles and having a small draft, the drifter can also provide information on waves not provided by conventional drifters. For release 6 (Table 1), the water depth generally exceeded the range of the ADCP (Fig. $5 \mathrm{~b}$ ), so instantaneous vertical motion of the drifter could not be determined. However, pitch and roll measurements (not shown) suggest wave frequencies of just a few seconds. To remove these unresolved wave motions, vertical velocities (relative to the ADCP) were smoothed with a 60 s moving average filter. Resulting time-averaged vertical velocities (Fig. $5 \mathrm{f}$ ) show moderate downwelling for $t=12-40 \mathrm{~min}$, likely because the drifter had reached and become trapped in the surface front and lateral convergence (consistent with observations that the drifter had joined a line of front trapped detritus around this time). The downwelling is also consistent with a region of enhanced backscatter (possibly because of organic detritus in the front or a region of enhanced turbulence). 

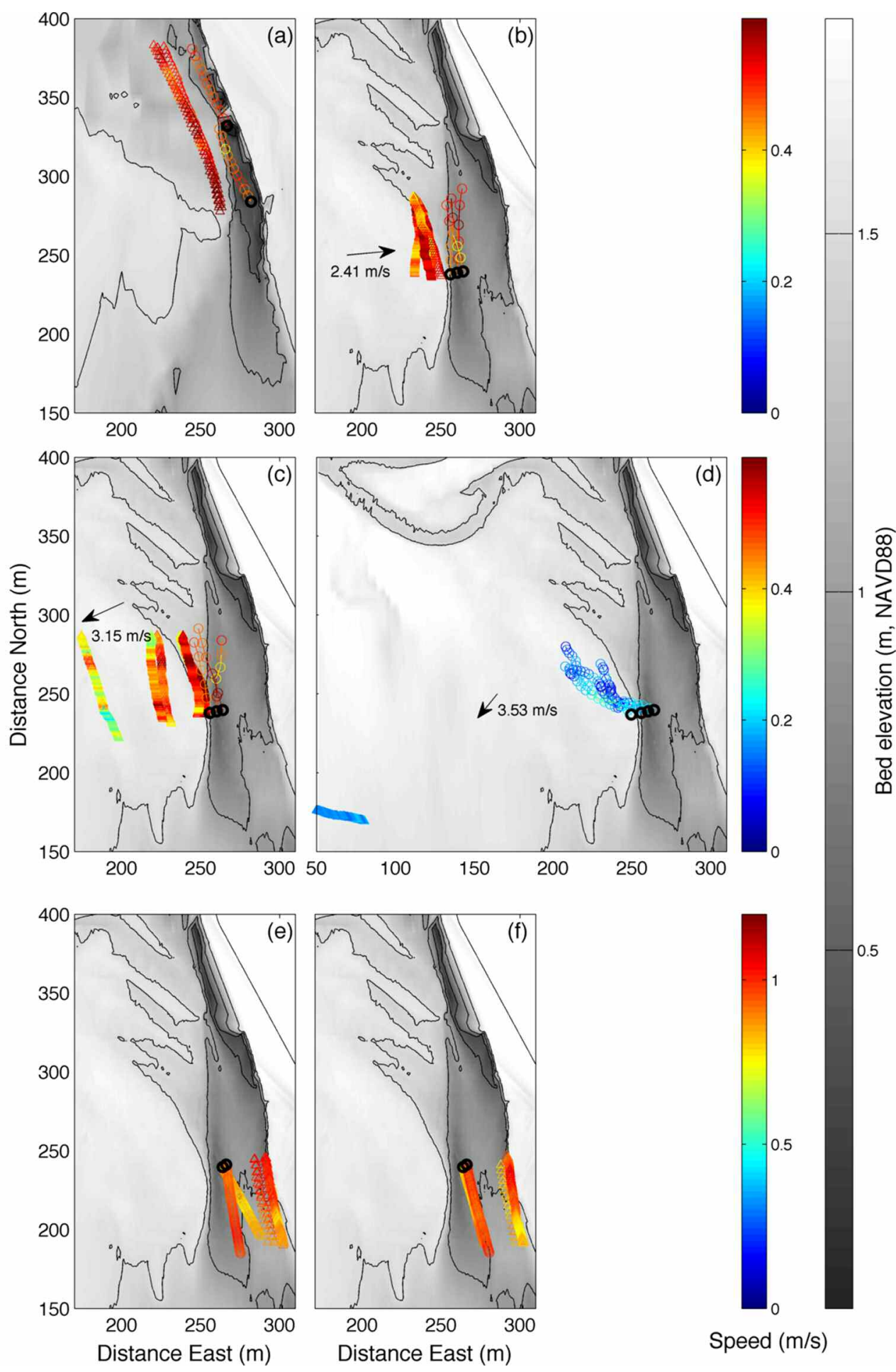

Fig. 10. Drifter tracks (triangles) colored by speed when they passed within the vicinity of fixed instrument locations (thick black circles). Drifter speeds were obtained by differencing GPS positions and smoothing over 8-12 s (depending on GPS sample rate). Colored circles show progressive vector plots of surface velocities (top range bin of width $0.1 \mathrm{~m}$, velocities smoothed over $1 \mathrm{~min}$ ) for the time after the drifter passed by. Bathymetry was measured by an RTK GPS survey (precision < 0.05 m) from 9 Oct 2008 (a), 7 July 2009 (b-f). (a)-(d) are flood tide releases (northward or westward movement, release numbers 1,5,6,7, Table 1); (e) and (f) show ebb tide releases (southward travel, releases 3,4, Table 1). Black arrows and text show concurrent wind speeds and directions (when data were available). 
Comparisons between velocities measured by drifter and by fixed instruments were limited because of the different locations and depths of the measurements. In particular, because of the instrument mounting, draft and blanking distances, the stationary ADCPs could not measure in flows shallower than $0.3 \mathrm{~m}$. However, in some instances, the drifters passed in the vicinity of fixed ADCPs and these tracks (colored by speed) are shown in Fig. 10, along with progressive vector plots of surface velocities recorded by the fixed instruments. The measurements from the fixed instruments are taken from the top range bin ( $0.1 \mathrm{~m}$ depth). Concurrent wind vectors are also plotted for times when wind data were available. Comparison between velocities in the channel and flats indicate high spatial variability (Fig. 10c). Nonetheless, the directions and speeds of the drifter resembled near-surface water velocities measured by the fixed instruments. These directions were clearly distinct from the wind directions, thus indicating that drifter motions were dominated by water flows, rather than windage.

\section{Discussion}

We have demonstrated use of a novel surface drifter suited for deployment in shallow environments, such as estuaries, tidal flats, or lakes. The drifter is designed for attachment of a small ADCP (e.g., Nortek Aquadopp) for current profiling, although the drifters can equally be used without an ADCP attached. High quality, high resolution data were obtained using a mounted pulse-coherent ADCP. In particular, the problem of phase-wrapping and associated velocity ambiguities (typically encountered by pulse-coherent measurements of moderate or strong velocities in an Eulerian reference frame, Lohrmann et al. 1990) was largely mitigated by use of Lagrangian measurements. Deployments over several tidal cycles allowed for identification of regions of bathymetrically steered flow along the edge of a tidal channel (resulting from a channel-edge front, Mullarney and Henderson 2011). ADCPs revealed flow features (such as wave motions, vertical velocities, and depth dependence of horizontal velocity) that would not be resolved by surface drifters alone. Furthermore, by measuring bed motion (relative to the drifter), ADCPs provided independent estimates of drifter velocity.

The design presented here offers potential for furthering our understanding of shallow flows. Other preliminary work (Mullarney and Henderson 2012) has used measurements from drifter-mounted ADCPs to calculate estimates of dissipation rates of turbulent energy using the structure function method of Wiles et al. (2006).

The drifter was designed to minimize windage, and during field trials (with winds $<5 \mathrm{~m} / \mathrm{s}$ ) drifters appeared to travel with surrounding water. However, an advantage of the drifter-mounted ADCPs is the direct measurement of water velocities relative to the ADCP. Therefore, any tendency for wind-slip relative to underlying water is removed from water velocity estimates. The drifter was assembled at low cost using off-the-shelf components. A disadvantage of the present system is that drifters need to be closely monitored to avoid loss (a limitation that can be overcome using telemetry, e.g., as on the surfzone drifters used by Schmidt et al. 2003).

\section{References}

Austin, J., and S. Atkinson. 2004. The design and testing of small, low-cost GPS-tracked surface drifters. Estuaries 27:1026-1029 [doi:10.1007/BF02803428].

Davis, R. E. 1985. Drifter observations of coastal surface currents during CODE: The method and descriptive view. J. Geophys. Res. 90:4741-4755 [doi:10.1029/JC090iC03p 04741].

Henderson, S. M., and J. C. Mullarney. 2013. Wave mixed, wind-generated near-surface shear observed over a tidal flat. Cont. Shelf Res. 60S:22-29 [doi:10.1016/j.csr.2012. 05.008].

Johnson, D., R. Stocker, R. Head, J. Imberger, and C. Pattiaratchi. 2003. A compact low-cost GPS drifter for use in the oceanic nearshore zone, lakes and estuaries. J. Atmos. Ocean. Technol. 20:1880-1884 [doi:10.1175/15200426(2003)020<1880:ACLGDF>2.0.CO;2].

Lhermitte, R., and R. Serafin. 1984. Pulse-to-pulse coherent Doppler sonar signal processing techniques. J. Atmos. Ocean. Technol. 1:293-308 [doi:10.1175/1520-0426(1984) 001<0293:PTPCDS>2.0.CO;2].

Lohrmann, A., B. Hackett, and L. P. Røed. 1990. High resolution measurements of turbulence, velocity and stress using a pulse-to-pulse coherent sonar. J. Atmos. Ocean. Technol. 7:19-37 [doi:10.1175/1520-0426(1990)007<0019:HRMO $\mathrm{TV}>2.0 . \mathrm{CO} ; 2]$.

$\longrightarrow$, and S. Nylund. 2008. Pulse coherent doppler systems-How far can we push it? In Proceedings of the IEEE/OES/CMTC Ninth Working Conference on Current Measurement Technology, 2008. IEEE [doi:10.1109/ CCM.2008.4480837].

MacMahan, J., J. Brown, and E. Thornton. 2009. Low-cost handheld global positioning system for measuring surfzone currents, J. Coastal Res. 25:744-754 [doi:10.2112/081000.1].

Mullarney, J. C., and S. M. Henderson. 2011. Hydraulically controlled front trapping on a tidal flat. J. Geophys. Res. 116 [doi:10.1029/2010JC006520].

— lent dissipation over a shallow tidal flat from pulse coherent Acoustic Doppler Profilers. In Proceedings of 33rd Conference on Coastal Engineering. 2012 [doi:10.9753/ icce.v33.currents.49].

Schmidt, W. E., B. T. Woodward, K. S. Millikan, R. T. Guza, B. Raubenheimer, and S. Elgar. 2003. A GPS-tracked surf zone drifter. J. Atmos. Ocean. Technol. 20:1069-1075 [doi:10. 1175/1460.1]. 
Thomson, J. 2012. Wave breaking dissipation observed with "SWIFT" drifters. J. Atmos. Ocean. Technol. 47(9):18661882 [doi:10.1175/JTECH-D-12-00018.1].

Wiles, P. J., T. P. Rippeth, J. H. Simpson, and P. J. Hendricks. 2006. A novel technique for measuring the rate of turbulent dissipation in the marine environment. Geophys. Res. Let. 33(21) [doi:10.1029/2006GL027050].
Zedel, L., A. E. Hay, R. Cabera, and A. Lohrmann. 1996. Performance of a single beam pulse-to-pulsecoherent Doppler profiler. IEEE J. Ocean. Eng. 21:290-297 [doi:10.1109/ 48.508159].

Submitted 17 March 2013

Revised 26 June 2013

Accepted 10 July 2013 